\title{
$\widehat{A}$ Madridge \\ madridge Journal of Dermatology \& Research \\ terconnecting Scientific World
}

Editorial Article

Open Access

\section{Lichen Planus Pigmentosus-Inversus}

\author{
El Jouari Ouiame ${ }^{1}$, Zaouguiahmed Anas $^{2}$, Senhaji Ghita ${ }^{1}$, Gallouj Salim ${ }^{1}$, Farihmoulay Hassan ${ }^{2}$ and Mernissifatima Zahra \\ ${ }^{\prime}$ Department of Dermatology Hassan II University Hospital, Fez, Morocco \\ ${ }^{2}$ Department of Urology Hassan II University Hospital, Fez, Morocco
}

\section{Article Info}

\begin{abstract}
*Corresponding author:
Department of Dermatology

Hassan II University Hospital

Morocco

Email: eljouariouiame@gmail.com
\end{abstract}

Received: December 14, 2021

Accepted: December 26, 2021

Published: December 30, 2021

Citation: Ouiame EJ, Nair AG, Anas Z, Ghita S, Salim G, Hassan F, Zahra M. Lichen Planus Pigmentosus-Inversus. Madridge J Dermatol Res. 2021; 5(1): 113-114. doi: $10.18689 / \mathrm{mjdr}-1000130$

\begin{abstract}
Copyright: ( $) 2021$ The Author(s). This work is licensed under a Creative Commons Attribution 4.0 International License, which permits unrestricted use, distribution, and reproduction in any medium, provided the original work is properly cited.
\end{abstract}

Published by Madridge Publishers

\begin{abstract}
Lichen planus pigmentosus inversus is a pigmentary cutaneous manifestation located on skin fold areas, and considered a rare variant of lichen planus pigmentosus. The pathogenesis appears to be related to a T lymphocyte-mediated, cytotoxic activity against basal keratinocytes. It presents as asymptomatic to mildly pruritic, hyperpigmented macules and/or patches involving intertriginous and flexural areas and skin folds in light-skinned individuals. The prominent histological characteristics are the lichenoid changes and prominent melanin incontinence. Lichen planus pigmentosus-inversus seems to be resistant to usual treatments. We report the characteristics of a new case of this rare entity.
\end{abstract}

Keywords: Lichen plan pigmentosus, Lichen plan pigmentosus-inversus, Rare variant, Folds.

\section{Introduction}

Lichen planus pigmentosus inversus (LPPI) is a pigmentary cutaneous disorder located on skin fold areas. We describe the clinical and dermoscopic features of this rare subtype of lichen.

\section{Case Presentation}

A 45-year-old male presented with 6 months history of asymptomatic, enlarging, hyperpigmented patches involving inguinal folds bilaterally. No associated pruritus or systemic symptoms or history of malignancy was present. No oral, hair, nail, or other skin lesions were reported. He denied any recent drug/medication use. Physical examination revealed a $3 \mathrm{~cm}$ well-defined, bilateral, brown, pigmented patches, following the inguinal folds, without erythema or scale [Figure 1]. No other lesions or skin, nail, or scalp changes were present. At deromscopy of the lesion rosettes with blue-grey perifollicular hyperpigmentation was observed [Figure 2]. The biological assessments were normal. Particularly, hepatitis $C$ serology was negative. Histological examination of the skin biopsy showed an atrophic epidermis with hypergranulosis, band-like lymphocytic infiltrate of the upper dermis with abundant colloid bodies, and marked pigmentary incontinence. Based on the clinical, dermoscopic and histologic, the diagnosis of lichen planus pigmentosus-inversus was made. Given the pauci lesionel and asymptomatic character of the lesions, the patient was treated by potent topical steroids, depigmenting cream, associated to strict photoprotection. At follow-up visits, the pigmented lesions became lighter after 6 months. A significant improvement was noted after one year. The decline is 24 months without recurrence. 


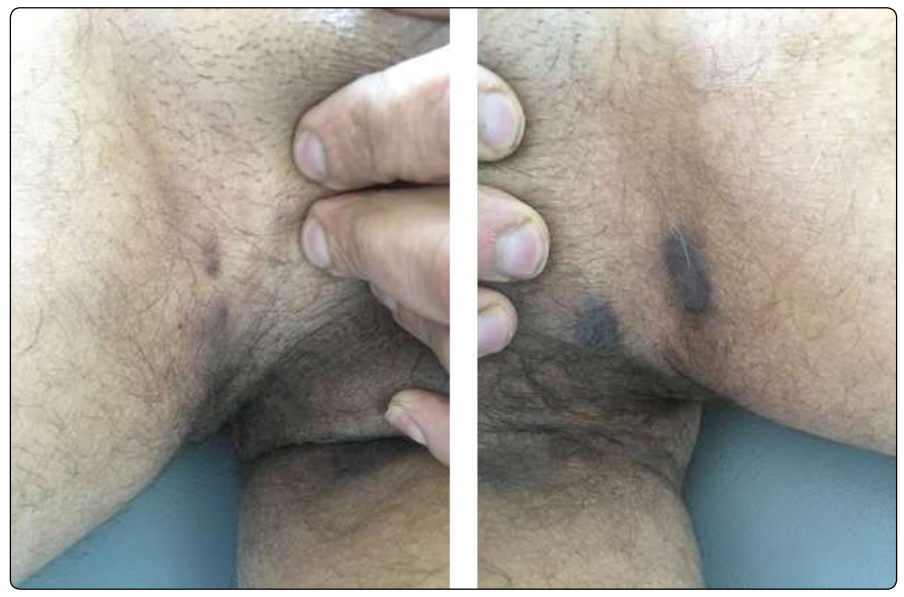

Figure 1. Pigmented patches of the inguinal folds

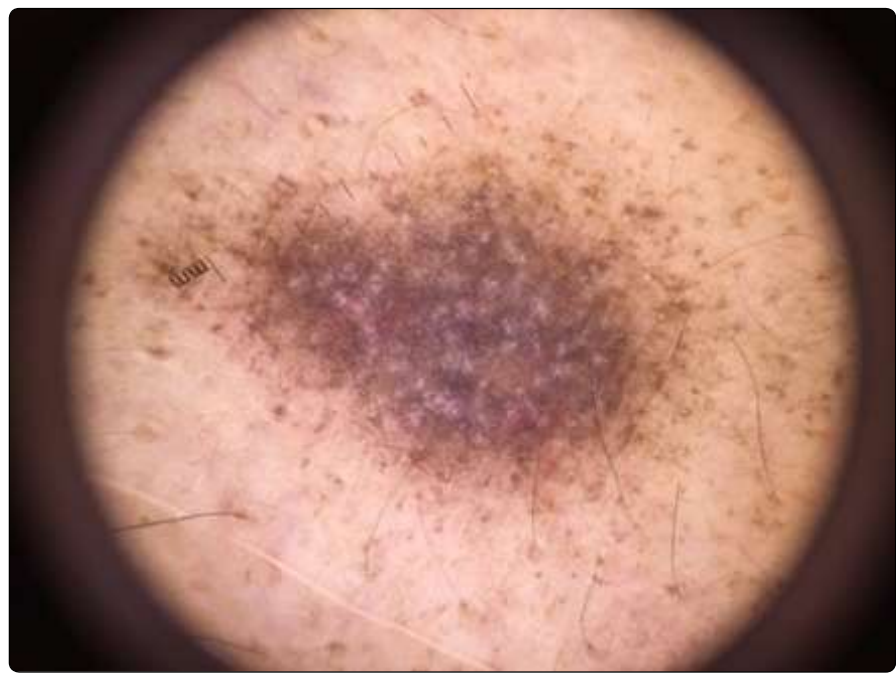

Figure 2: Dermoscopy showing rosettes with blue-grey perifollicular hyperpigmentation

\section{Discussion}

Lichen planus pigmentosus-inversus is a rare variant of lichen planus, with less than 20 cases reported in the medical literature [1].It affects individuals with light-skinned individuals in non-sun exposed, intertriginous and flexural areas and skin folds, with a worldwide distribution [2]. The etiology and pathogenesis of LPPI is unclear. Some authors have favored the mechanism of LPPI to be cytotoxic activity against basal keratinocytes mediated by CD8+ T-cell lymphocytes, as is believed to be the case in classic LP [3]. External mechanical stimuli, such as friction (Koebner's phenomenon) and wearing tight under clothes, are a suggested explanation for the isolated distribution of hyperpigmented lesions in intertriginous areas [4]. Clinically, LPP-inversus is characterized by dark-brown hyperpigmented macules and patches [5], those being the most frequently found lesions and not the traditional papules [2], predominantly located in the intertriginous and flexural areas and skin folds [6], with no itching/symptoms in the majority of patients or with slight pruritus in a small proportion of the patients [5]. The axillae and groin seem to be the most commonly affected areas [2] and tend to be bilateral in most cases. Other skin folds such as the neck, abdomen, popliteal regions, inframammary folds, antecubital fossae, waist, inner wrist and auricular sulci have been also involved [5]. Nail, hair, and mucous membranes are usually not affected, as with classic lichen planus [3].The differential diagnosis includes fixed drug eruption, acanthosis nigricans, candida intertrigo, erythrasma, post-inflammatory hyperpigmentation, lichenoid toxic dermatitis or ashy dermatosis [6]. Histologically, it corresponds to an orthokeratotic, atrophic epidermis with variably prominent lichenoid inflammation containing lymphocytes and histiocytes. There is prominent pigmentary incontinence and melanin containing macrophages in the superficial dermis. The melanin deposition is in the superficial dermis [1]. Therapeutic management of LPPI is often challenging for both the patients and physicians. Pigmented plaques tend to persist for months. Despite some authors suggesting that treatment with medium or high-potency topical corticosteroids or calcineurin inhibitors could accelerate the healing process [4], LPPI seems to be resistant to different treatments such as topical steroids, oral steroids, and topical tacrolimus. In a few cases, the lesions were improved or disappeared spontaneously after several months without any treatment [5].

\section{Conclusion}

LPPI seems to be under reported, which is probably because it is often misdiagnosed. It should be considered in the differential diagnosis of cutaneous pigmentation exclusively located in flexural areas.

\section{References}

1. Gaertner E, Elstein W. Lichen planus pigmentosus-inversus: Case report and review of an unusual entity. Dermatology Online Journal. 2012; 18(2): 11.

2. Hugo Rocha Barros et al. Lichen planus pigmentosus inversus. An Bras Dermatol. 2013; 88(6 Suppl 1): 146-149. doi: 10.1590/abd1806-4841.20132599

3. Nurmohamed S, Hardin J, Haber RM. Lichen planus pigmentosus inversus in children: Case report and updated review of the literature. Pediatr Dermatol. 2017; 35(1): e49-e51. doi: 10.1111/pde.13369

4. Mohamed M, Korbi M, Hammedi F, Youssef M, Soua Y, Akkari H, et al. Lichen planus pigmentosus inversus: A series of 10 Tunisian patients. International Journal of Dermatology. 2016; 55(10): 1088-1091. doi: 10.1111/ijd. 13295

5. Chen S, Sun W, Zhou G, Chen S, Lu X. Lichen planus pigmentosusinversus: Report of three Chinese cases and review of the published work. J Dermatol. 2015; 42(1): 77-80. doi: 10.1111/1346-8138.12693

6. Ghorbel HH, Badri T, Brahim EB, Fenniche S, Benmously R, Mokhtar I. Lichen planus pigmentosus inversus. Indian J Dermatol Venereol Leprol. 2014; 80(6): 580-580. doi: 10.4103/0378-6323.144234 